\title{
Vibration control of a flexible rotor suspended by shape memory alloy wires
}

Alves, Marco Túlio Santana; Steffen Jr., Valder; Castro dos Santos, Marina; Savi, Marcelo Amorim; Enemark, Søren; Santos, IImar Ferreira

Published in:

Journal of Intelligent Material Systems and Structures

Link to article, DOI:

$10.1177 / 1045389 \times 18758179$

Publication date:

2018

Document Version

Peer reviewed version

Link back to DTU Orbit

Citation (APA):

Alves, M. T. S., Steffen Jr., V., Castro dos Santos, M., Savi, M. A., Enemark, S., \& Santos, I. F. (2018). Vibration control of a flexible rotor suspended by shape memory alloy wires. Journal of Intelligent Material Systems and Structures, 29(11), 2309-2323 . https://doi.org/10.1177/1045389X18758179

\section{General rights}

Copyright and moral rights for the publications made accessible in the public portal are retained by the authors and/or other copyright owners and it is a condition of accessing publications that users recognise and abide by the legal requirements associated with these rights.

- Users may download and print one copy of any publication from the public portal for the purpose of private study or research.

- You may not further distribute the material or use it for any profit-making activity or commercial gain

- You may freely distribute the URL identifying the publication in the public portal 


\title{
Vibration Control of a Flexible Rotor Suspended by SMA Wires
}

\author{
Marco Túlio Santana Alves ${ }^{1}$, Valder Steffen $\mathrm{Jr}^{2}$, Marina Castro dos Santos ${ }^{3}$, Marcelo \\ Amorim Savi ${ }^{3}$, Søren Enemark ${ }^{4}$ and Ilmar Ferreira Santos ${ }^{4}$
}

(1) Federal University of Bahia, (2) Federal University of Uberlândia, (3) Federal University of Rio de Janeiro, (4) Technical University of Denmark

\begin{abstract}
The present contribution is devoted to the study of the influence of shape memory alloys on the dynamic behavior of flexible rotors. In this sense, a suspension composed by pseudoelastic SMA wires that are connected to a rotor-bearing test rig was designed. To evaluate the performance of the system, both numerical and experimental investigations are carried out. The suspension stiffness can vary, especially in the pseudoelastic region, so that this variation takes place per a hysteretic cycle denoting energy dissipation whenever the loading magnitude is sufficient to induce a phase transformation. The constitutive model used to describe the SMA behavior is a modified version of the Brinson model for the one-dimensional case. To provide all thermomechanical properties of SMA wire, a complete characterization process was performed. Due to numerical reasons the size of the model of the rotating system was reduced. Finally, numerical and experimental results demonstrate the success of SMA applied to the suspension of rotating machines as an interesting alternative for vibration control.
\end{abstract}

\section{Introduction}

The use of smart materials with the intention of mitigating vibration in rotating machines has been increasingly investigated by various researchers. However, there is a category of material still not fully explored for this purpose, namely the SMA (Shape Memory Alloy), which points out a new direction in the field of vibration control of rotating machines. SMA exhibits characteristics of shape memory and pseudoelasticity depending on the thermomechanical state. Thus, its stiffness can vary, especially in the pseudoelastic region, where this variation takes place, per a hysteretic cycle denoting energy dissipation, once the crystallographic structure migrates from austenite to martensite (and vice-versa) whenever the loading magnitude is sufficient to induce this phase transformation. 
These capabilities of SMA with respect to rotating machines have been previously investigated in a few publications. Nagaya et al. (1987) are some of the pioneers in using this family of materials applied to vibration control of rotors. They used SMA springs to change the bearing support stiffness by either heating or cooling the springs. Liu et al. (1994) investigated and proposed the use of SMA wires attached to the housing of hydrodynamic bearing to control the vibration, so that its stiffness reduces (softening) while the rotor accelerates and increases (hardening) while the rotor slows down. Both the behaviors are nonlinear and the pseudoelastic SMA wires play the role of energy dissipation device. Nie and Yan (2000) designed a smart support system to pass through critical speeds of an aeroengine. The principle of operation is based on an active switching of stiffnesses, where the SMA wires work as actuators. In this way, the engine has two different stiffness connections, so that this characteristic is useful to switch conveniently the stiffness in run-up and run-down operations to reduce the vibration amplitude when crossing the critical speeds. In their work, Gupta et al. (2003) propose the employment of SMA wires embedded in shafts composed by epoxy resin and fiberglass to modify their stiffness. The wires are stretched before they are embedded into the shaft so that an axial compression is induced, increasing its stiffness. Then, by using electric current it is possible to change the shaft stiffness conveniently. He et al. (2007a,b) proposed a selfoptimizing support system where SMA springs are used to construct a bearing pedestal. In addition, by using the principle of dynamic vibration absorbers they calculated and changed the stiffness of the pedestal to set the rotor-bearing system close to the antiresonance condition. Lees et al. (2007) applied SMA to a bearing pedestal by means of a winding of wires to change its stiffness by Joule effect. Atepor (2008) applied SMA elements integrated within glass epoxy composite plates and shells resulting the design of a novel smart bearing based on the principle of antagonistic action. Zhu et al. (2009) developed and applied a model based on multivariate statistical analysis vibration control of rotor systems with SMA. More recently, Borges et al. (2013) used helical springs made of SMA to control the vibration of a flexible rotor. They employed the general concept of dynamic vibration absorbers to model the system, so that the mass of the bearing where the SMA springs are located is considered as the secondary mass. Besides, a control law based on Fuzzy Logic was employed, in such a way that the transfer function correlates the spring temperature with its stiffness. In the same year, Silva et al. (2013) investigated the behavior of a rotordynamic nonsmooth SMA system where it is modeled as a Jeffcott rotor with two degrees of freedom. The focus relied on a comparison between the rotor responses with linear elastic support and those from the rotor with an SMA support. In addition, the dependence on the temperature was also investigated. It is noteworthy to mention that both compression and tension actions on the SMA element were allowed. Ma et al. (2014) described the design, manufacturing and evaluation of a smart support with elements of SMA. Based on this concept, the support can provide both variable stiffness and damping with respect to three parameters, namely: temperature, vibration amplitude and excitation frequency. Enemark et al. (2015) investigated experimentally how pseudoelastic SMA springs influence the dynamic behavior of a rotor-bearing system with low damping due to passive magnetic bearings. It was observed that the higher the temperature the stiffer the support. In addition, the hysteretic behavior of the system was evaluated. Therefore, both the amplitude responses through the critical speeds and the mode shapes were changed in order to reduce vibration. As an extended version 
of above mentioned paper, Enemark and Santos (2016a) presented a deeper analysis by comparing theoretical and experimental results proving, in terms of vibration suppression, the advantage of applying shape memory alloy to a rotor-bearing system. Yogaraju et al. (2016), based on experimental studies, observed that shape memory alloy (SMA) can be used as a medium to apply necessary forces at identified locations to obtain the desired profile shapes for a multi-lobe bearing configuration facilitating the development of semiactive journal bearings. Finally, Yuan et al. (2017) presented a very detailed review about actuators driven by shape memory alloy, more specifically rotary actuator, highlighting its specificities and potentialities for new applications in the future. Thus, a rotating machine could be benefited by some of the concepts explored.

The present contribution deals with study of dynamic behavior of a horizontal rotorbearing system suspended by shape memory alloys pseudoelastic wires, in order to verify the feasibility of either passive or semi-active control devices for rotating machines in the future. In terms of control, the strategy is based upon the change of stiffness by heating/cooling the suspension and the addition of some damping by cyclic phase transformation due to mechanical loading. The performance of the proposed system is investigated for the following conditions: rotor at steady state motion with several temperatures, rotor at steady state motion with varying temperature and transient motion with several temperatures. To be effective, the SPW is mounted along the horizontal plane and it is located at the position of one of the rotor bearings. To reduce the computational cost, the size of the rotor model obtained from FEM is reduced by neglecting the higher modes. The constitutive model used to describe the SMA behavior is a modified version of the model by Brinson for the one-dimensional case, as performed by Enemark et al. (2014).

This paper is organized according to five sections, as follows. After a brief overview presented in the introduction, the rotor model is derived by using the finite element method (FEM); the concept of suspension system, its characteristics as well as its modeling are then presented; a comparison between numerical and experimental results is discussed; and finally, the conclusions are summarized.

\section{The Experimental Apparatus}

Figure 1 depicts an overview of the experimental apparatus, highlighting the main parts of the test rig. Basically, it is encompassed by a flexible rotor-bearing system, a heating device and the rotor suspension. As designed by Alves (2015), the suspension, composed of pre-tensioned wires, is encapsulated inside a heating chamber to keep the temperature of the air from the heat gun under control, as detailed in Fig. 2. The main physical properties related to the rotor-bearing system are shown in Tab. 1. The SMA wires are made of nickel and titanium (Ni-Ti alloy), whose total length is $160 \mathrm{~mm}$. The choice of the wire diameter $(0.25 \mathrm{~mm})$ was made by considering two reasons, as follows: first, to provide condition to assume isothermal distribution of temperature along the cross sectional area; second, to make the suspension flexible enough to allow phase transformation through the wire deformation.

The suspension of bearing \#2 is composed basically of a bearing housing supported by a flexible frame composed by two steel rulers, as can be seen in Fig. 3. In spite of the fact that most of the bearings have similar stiffnesses in both directions, this concept was adopted to allow high amplitude of vibration along to the horizontal plane, since 


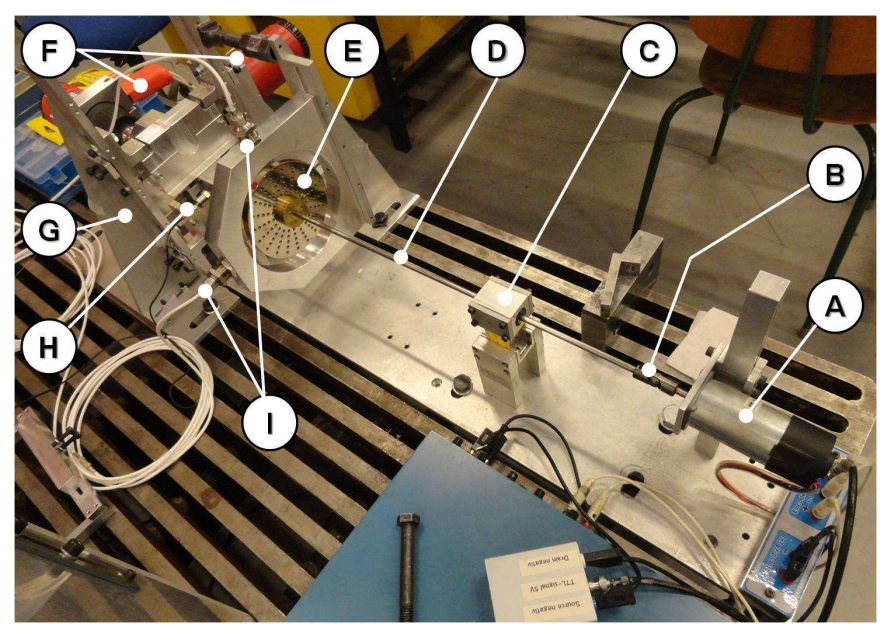

Figure 1: Experimental Apparatus: (A) DC motor/encoder; (B) coupling; (C) bearing \#1; (D) flexible shaft; (E) disc; (F) heat guns; (G) suspension system; (H) accelerometer and (I) proximity probes.

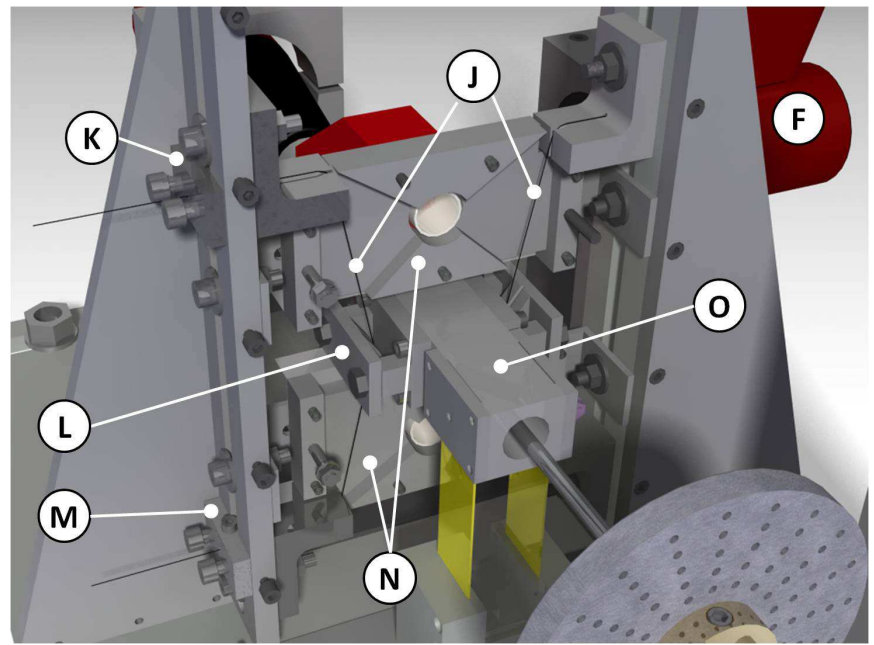

Figure 2: Detailed view of suspension by pre-tensioned wires (SPW): (F) heat gun; (J) PE SMA wires; $(\mathrm{K}),(\mathrm{L})$ and $(\mathrm{M})$ tensioners; $(\mathrm{N})$ heating chamber and $(\mathrm{O})$ bearing \#2. 
the architecture of the suspension was designed to work on the same plane. Thus, based on strength of materials, a relationship between axial (vertical direction) and flexural (horizontal) stiffnesses $\left(k_{z} / k_{y}\right)$ can be calculated as follows

$$
\frac{k_{z}}{k_{y}}=\frac{E_{b} A_{b} / L_{b}}{12 E_{b} I_{b} / L_{b}^{3}}=\frac{E_{b} w h / L_{b}}{12 E_{b}\left(w h^{3} / 12\right) / L_{b}^{3}}=\left(\frac{L_{b}}{h}\right)^{2}
$$

where, for the steel ruler, $w, h$ and $L_{b}$ are the width, thickness and length, respectively. In addition, $A_{b}, I_{b}$ and $E_{b}$ are the cross-sectional area, moment of inertia of area and Young's modulus, respectively. Therefore, the result shown by Eq. (1), explains the huge discrepancy in the order of magnitude between the stiffnesses along to horizontal and vertical direction, as presented in the Tab.1 and depicted schematically in Fig. 3. In the present paper the ratio $L_{b} / h=64$, such that $k_{z} \simeq 4,100 k_{y}$. However, it is noteworthy to mention that the stiffnesses presented in the Tab. 1 were obtained after parameter adjustments, as performed by Alves (2015).

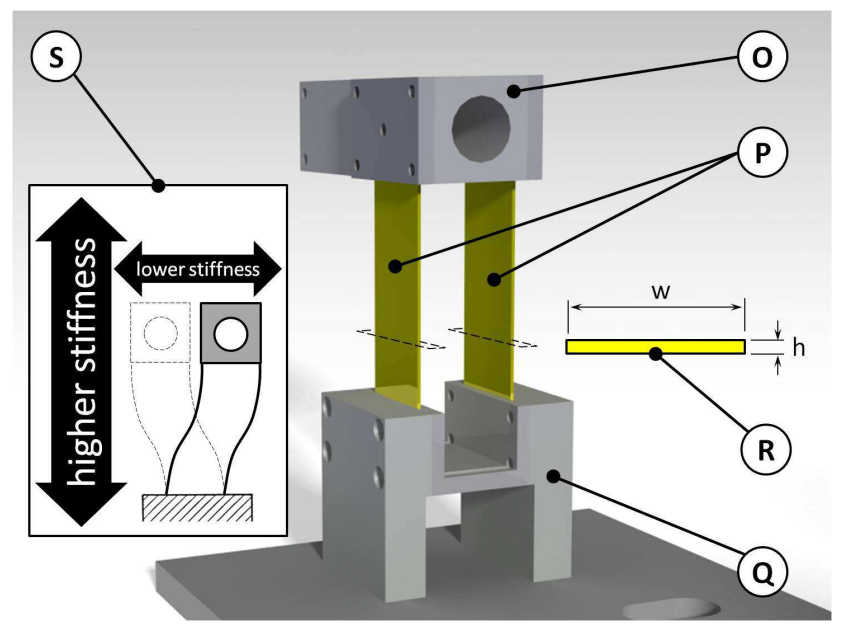

Figure 3: Detailed view of bearing \#2: $(\mathrm{O})$ bearing \#2's housing; (P) flexible frame; $(\mathrm{Q})$ bearing \#2's base; $(\mathrm{R})$ steel ruler's cross section and $(\mathrm{S})$ schematic comparison between flexural and axial stiffnesses.

\section{System Modeling}

The models used to describe the behavior of the complete system are presented separately, according to each sub-system. First, the rotor formulation and its properties are shown. Then, the general characteristics and properties of the suspension, as based on pre-tensioned wires, are discussed. Finally, the truncation criteria and the reduced model of the complete system are presented.

\subsection{Rotor Model}

The dynamic response of the considered mechanical system can be modeled by using variational mechanics equations as based on the Hamilton's Principle. For this aim, the 
Table 1: Physical characteristics of rotor-bearing system and imbalance.

\begin{tabular}{ll}
\hline Shaft & steel \\
material & 6 \\
$\quad$ diameter $[\mathrm{mm}]$ & 581 \\
$\quad$ length $[\mathrm{mm}]$ & 205 \\
$\quad$ Young's modulus $[\mathrm{GPa}]$ & 7800 \\
$\quad$ density $\left[\mathrm{kg} / \mathrm{m}^{3}\right]$ & 0.129 \\
$\quad$ mass $[\mathrm{kg}]$ & \\
Disc & steel \\
$\quad$ material & 120 \\
$\quad$ diameter $[\mathrm{mm}]$ & 11 \\
$\quad$ thickness $[\mathrm{mm}]$ & 0.860 \\
$\quad$ mass $[\mathrm{kg}]$ & \\
Bearing \#1 & 0.140 \\
$\quad$ mass $[\mathrm{kg}]$ & $1.25 \times 10^{5}$ \\
$\quad$ stiffness (horizontal direction) $[\mathrm{N} / \mathrm{m}]$ & $3.83 \times 10^{8}$ \\
stiffness (vertical direction) $[\mathrm{N} / \mathrm{m}]$ & \\
Bearing \#2 & 0.407 \\
$\quad$ mass $[\mathrm{kg}]$ & $1.31 \times 10^{4}$ \\
$\quad$ stiffness (horizontal direction) $[\mathrm{N} / \mathrm{m}]$ & $1.35 \times 10^{8}$ \\
stiffness (vertical direction) $[\mathrm{N} / \mathrm{m}]$ & \\
Coupling & $2.00 \times 10^{4}$ \\
$\quad$ stiffness (horizontal direction) $[\mathrm{N} / \mathrm{m}]$ & $2.60 \times 10^{4}$ \\
stiffness (vertical direction) $[\mathrm{N} / \mathrm{m}]$ & \\
Imbalance & 45.0 \\
imbalance $[\mathrm{g} \times \mathrm{mm}]$ & \\
\hline
\end{tabular}

Table 2: List of equipments and instrumentation installed to the test rig.

\begin{tabular}{lll}
\hline Equipment & Brand & Model \\
\hline DC motor/encoder & RS Components & $715-112$ \\
power supply (DC motor) & Bang \& Olufsen & SN16A \\
acquisition card & D-Space & CP1103 \\
accelerometer & B\&K & Type 4384 \\
charge amplifier & B\&K & Type 2635 \\
proximity probes & Vibro-Meter & TQ403 \\
driver (proximity probes) & Vibro-Meter & IQS450 \\
thermocouple/universal transmitter & PR Electronics & 4114 \\
power supply (universal transmitter) & Mascot & $2183-24 V D C / 1 A$ \\
heat guns & Am-Tech & V2260 - 230-240V \\
relay transistor & Crydom & CL240D10 \\
power supply (heat gun motor) & Radiofoni & 40 VDC/3A \\
\hline
\end{tabular}


strain energy of the shaft and the kinetic energies of the shaft and discs are calculated. An extension of Hamilton's Principle makes possible to include the effect of energy dissipation. The parameters of the bearings are considered in the model by using the principle of the virtual work. For computation purposes, the FEM is used to discretize the structure so that the energies calculated are concentrated at the nodal points. Shape functions are used to connect the nodal points. The model obtained as described above is represented mathematically by the set of differential equations (Lalanne and Ferraris, 1997) given by Eq. (2).

$$
\mathbf{M} \ddot{\mathbf{x}}+[\mathbf{C}+\dot{\phi} \mathbf{G}] \dot{\mathbf{x}}+\left[\mathbf{K}+\ddot{\phi} \mathbf{K}_{G}\right] \mathbf{x}=\mathbf{F}_{u}+\mathbf{F}_{s}
$$

where $\mathbf{x}$ is the vector of generalized displacements; $\mathbf{M}, \mathbf{K}, \mathbf{K}_{G}, \mathbf{C}$ and $\mathbf{G}$ are matrices of inertia, stiffness, stiffness due to transient motion, damping (that may include proportional damping) and gyroscopic (rotational speed dependent) effect. In addition, $\mathbf{F}_{u}$ and $\mathbf{F}_{s}$ are the vectors of external forces due to both the unbalance and to the suspension by pseudoelastic SMA wires, respectively. The FEM model considers 4 DOFs per node, namely two displacements (along the directions $x$ and $z$ ) and two rotations (around the axes $x$ and $z$ ), respectively. For the simulation, the excitation force is due to unbalance and $F_{s}$ is given by Eq. (12). The rotor-bearing system shown in Fig. 4 was discretized into 16 nodes, as depicted in Fig. 5. In this model, the suspension is located as close as possible to the bearing \#2 (at node \#16). The coupling is located at node $\# 1$, the bearing $\# 1$ is at the node $\# 5$ and the disc is placed at the node $\# 12$. The properties of bearings and coupling were obtained experimentally as shown by Alves (2015). These properties together with the rotor properties are presented in Tab. 1. For this rotor-bearing system, the mode shapes for the first and second modes are shown in Fig. 6(a) and Fig. 6(b), respectively. It is important to mention that the first mode shape, as clearly shown, enhances the effectiveness of the suspension, just as defined its architecture. On the other hand, due to the discrepancy between the stiffnesses along both directions as discussed earlier, the gyroscopic effect takes place exactly in the second mode, precisely when the rotor-bearing system exhibits an extremely flat orbit along the vertical direction, such that the dynamics of the system has no action onto the suspension.

\subsection{SMA Constitutive Model}

The behavior of SMA for the one-dimensional case is described by the constitutive models proposed by Brinson (1993), Brinson and Huang (1996) and Bekker and Brinson (1998). In the present paper the focus is on the pseudoelastic behavior of the material. Thus, we can neglect the twinned martensite since the lowest operational temperature (room temperature) is higher than the martensitic start temperature $M_{s}$ for the material used in the SPW, as can be seen in the Tab. 3. So, by considering the characteristic temperatures of SMA and the operational temperature range, the constitutive equation that governs its behavior is given by

$$
\sigma=E\left(\epsilon-\epsilon_{L} \xi\right)
$$




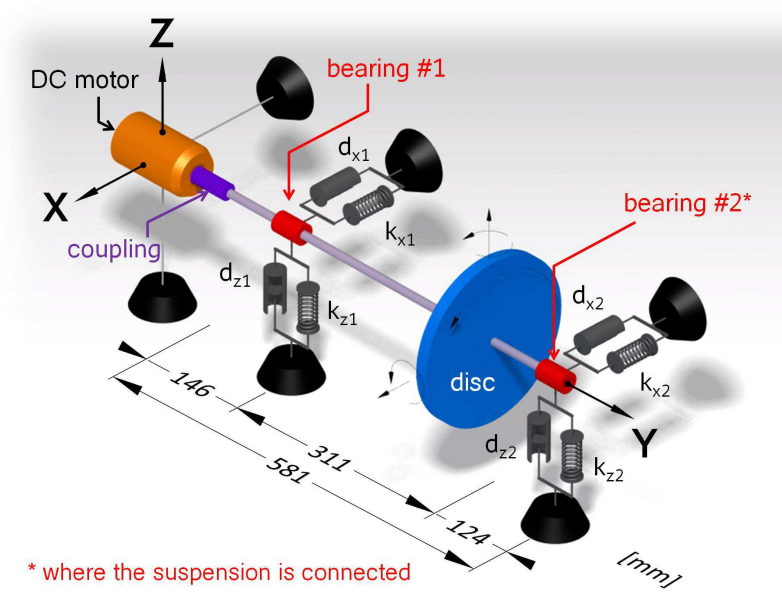

Figure 4: Schematic of the rotor-bearing system.

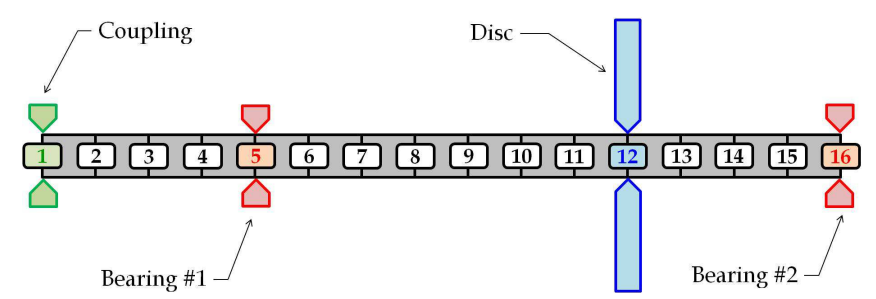

Figure 5: Schematic of shaft discretization.

(a)

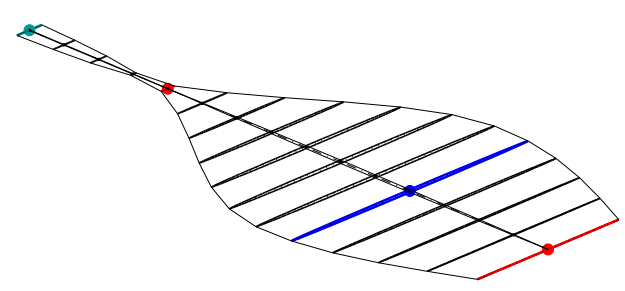

(b)

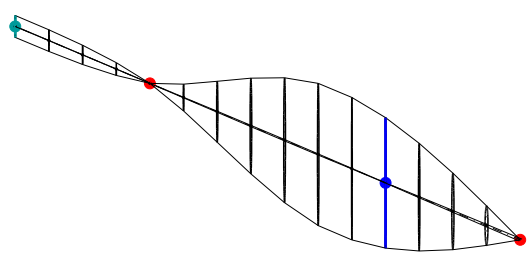

Figure 6: Mode shapes of the rotor-bearing system: (a) first mode and (b) second mode. (green node $\rightarrow$ coupling; red nodes $\rightarrow$ bearings; blue node $\rightarrow$ disc) 
where $\sigma$ is the axial stress, $\epsilon$ is the actual strain, $\xi$ is de martensite volume fraction and $\epsilon_{L}$ is the residual strain dependent upon each alloy. According to the original Brinson's model both the twinned and detwinned martensite can coexist. However, only the detwinned martensite will be considered in this contribution. Furthermore, $E=E_{A}+\xi\left(E_{M}-E_{A}\right)$, where $E_{M}$ and $E_{A}$ are, respectively, the Young's moduli for martensitic and austenitic crystallographic structures, and $\epsilon_{L}$ is the residual strain due to phase transformation. It is important to mention that in the context of this contribution, some terms are not considered, such as thermoelastic expansion and any change in the material due to mechanical deformation (Enemark et al., 2014).

During the forward transformation the evolution of the martensite volume fraction $\xi$ is governed by

$$
\begin{aligned}
& x_{f}=\frac{\sigma-\sigma_{m_{s}}}{\sigma_{m_{f}}-\sigma_{m_{s}}} \\
& f_{f}=f\left(x_{f}\right) \\
& \xi=\xi_{0}+\left(1-\xi_{0}\right) f_{f}
\end{aligned}
$$

For the reverse transformation one has

$$
\begin{aligned}
& x_{r}=\frac{\sigma-\sigma_{a_{s}}}{\sigma_{a_{s}}-\sigma_{a_{f}}} \\
& f_{r}=f\left(x_{r}\right) \\
& \xi=\xi_{0} f_{r}
\end{aligned}
$$

where $f_{f}$ and $f_{r}$ are the so-called hardening functions. The mandatory requirement for this function is that the horizontal tangents at the boundaries ensure smooth transition between linearly elastic regions and transformation regions. Thus, the proposal is to use a cubic Bézier curve to control the parameters instead the one based on a cosine function, as originally considered in the Brinson's model. The cubic Bézier curve, as shown in Fig. 7, ensures genuine smoothness (infinitely differentiability) as shown previously by Alves et al. (2015). For more details regarding the mathematical development, refer to Brinson and Huang (1996), Bekker and Brinson (1998) and Enemark and Santos (2016b).

The pseudoelastic SMA wires used in this contribution were purchased from website Amazon ${ }^{\circledR}$ accessing directly http://www.amazon.com/dp/B001385FYY/ and all their thermomechanical properties can be found in the Tab. 3 . 


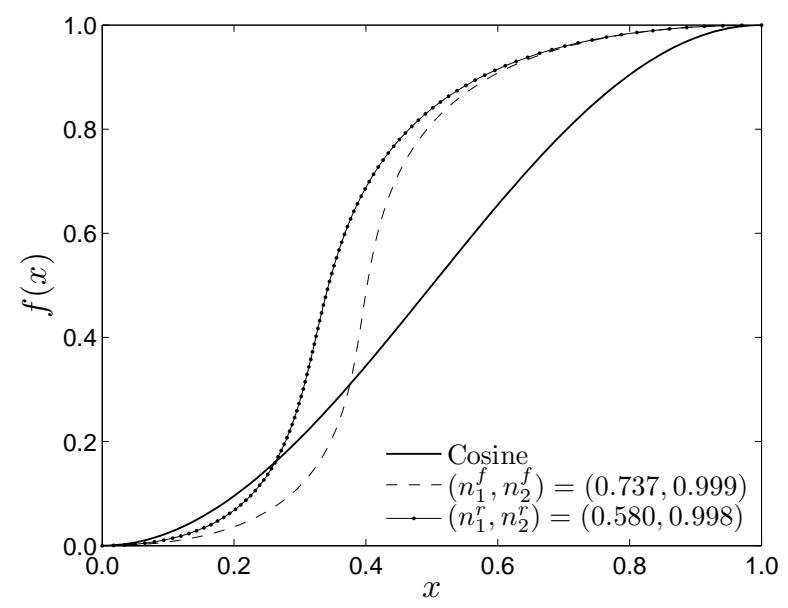

Figure 7: Hardening functions in the forward and reverse transformations.

\subsection{Thermomechanical Characterization}

Thermomechanical analysis of SMAs needs to establish a proper characterization that identify the main aspects of the SMA. Basically, different experimental tests are developed to perform the characterization. Phase transformation temperatures are usually measured from DSC (Differential Scanning Calorimetry) tests. Mechanical properties are evaluated from mechanical tests, usually performed with a universal testing machine.

Temperature plays an essential role in the thermoelastic martensite phase transformation and, therefore, physical properties, such as the electrical resistivity and elastic modulus, change with temperature. The determination of thermal properties is fundamental to the design of actuators based on SMAs, targeting advanced applications.

\subsubsection{DSC Analysis:}

The Netzsch ${ }^{\circledR}$ DSC 200F3 is the calorimeter model used to characterize the NiTi wires of the test rig.

DSC test analyzes phase temperature of SMA sample by monitoring temperature and heating. The SMA sample is placed in a small crucible and measurements are compared with a reference sample, that can be a stable metal without phase transformation in the temperature range examined. The calorimeter makes measurements of temperature and energy occurring during the process, rate of $10^{\circ} \mathrm{C} / \mathrm{min}$ is used for thermal characterization.

A typical measurement of the DSC test is presented in Fig. 8 that shows phase transformation temperatures: $M_{s}, M_{f}, A_{s}$ and $A_{f}$. These temperatures represent the start and finish of martensitic formation and the start and finish of the formation of austenite. These measurements are done considering the tangent method.

\subsubsection{Isothermal stress-strain tests:}

Mechanical properties are usually evaluated from universal testing machines. Cyclic tensile tests are performed using an INSTRON ${ }^{\circledR}$ Model 5902 with an environmental 


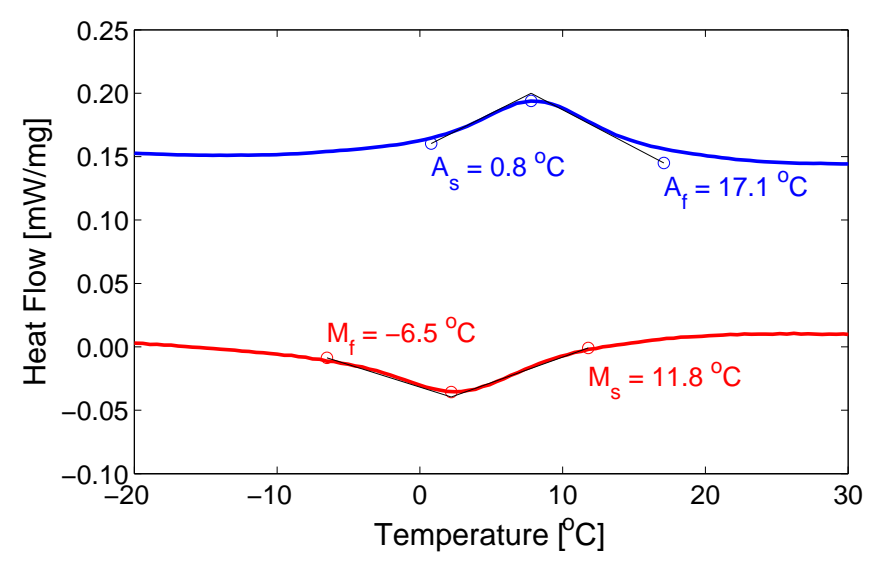

Figure 8: Differential Scanner Calorimetry test of the SMA wire.

chamber. Figure 9 shows the stress-strain curve at temperatures around $30^{\circ} \mathrm{C}$ and $50^{\circ} \mathrm{C}$. A typical pseudoelastic curve is achieved where it is possible to identify elastic moduli of austenite and martensite, and a hysteresis loop associated with phase transformation. The elastic coefficients can be obtained by the slope of the linear elastic response. At the same time the $C_{A}$ and $C_{M}$ values can be obtained by tracing tangents at the stress versus strain curves.

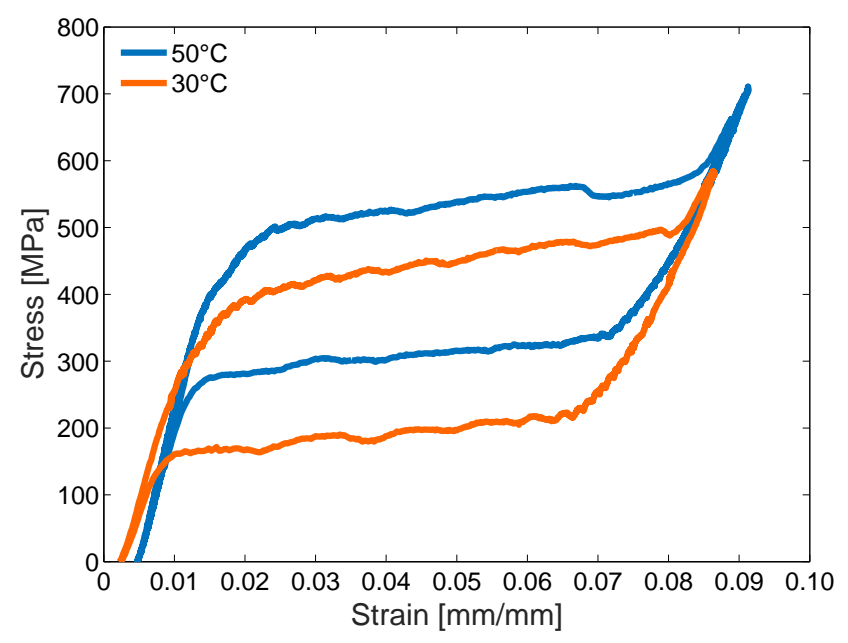

Figure 9: Tensile test of the SMA wire.

According to Brinson (1993) the constants $C_{M}$ and $C_{A}$ are material properties that describe the relationship of temperature and the critical stress to induce transformation, $\sigma_{\text {crit }}$. The objective of this test is to establish the coupling between phase transformation critical stress and temperature, represented by the slopes of the curves in Fig. 10. Both $C_{M}$ and $C_{A}$ adopted in this contribution correspond to the average between the slopes of the $M_{s}$ and $M_{F}$, and $A_{s}$ and $A_{F}$ curves, respectively.

Table 3 presents a summary of the thermomechanical characterization. 


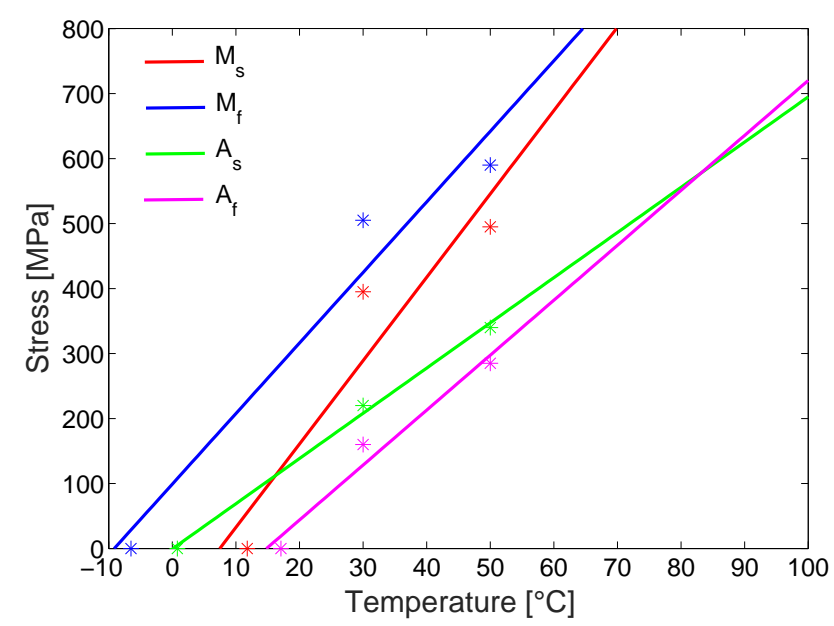

Figure 10: $C_{A}$ and $C_{M}$ from stress-strain tests for different temperatures.

Table 3: Thermomechanical properties for the PE SMA wire.

\begin{tabular}{clr}
\hline$\epsilon_{L}$ & residual strain [\%] & 4.08 \\
$E_{A}$ & Young's modulus of austenite $[\mathrm{GPa}]$ & 44.5 \\
$E_{M}$ & Young's modulus of martensite $[\mathrm{GPa}]$ & 25.8 \\
$C_{A}$ & stress influence coeff. of aust. $\left[\mathrm{MPa} /{ }^{\circ} \mathrm{C}\right]$ & 7.70 \\
$C_{M}$ & stress influence coeff. of mart. $\left[\mathrm{MPa} /{ }^{\circ} \mathrm{C}\right]$ & 11.84 \\
$A_{s}$ & austenitic start temperature $\left[{ }^{\circ} \mathrm{C}\right]$ & 0.8 \\
$A_{f}$ & austenitic finish temperature $\left[{ }^{\circ} \mathrm{C}\right]$ & 17.0 \\
$M_{s}$ & martensitic start temperature $\left[{ }^{\circ} \mathrm{C}\right]$ & 11.8 \\
$M_{f}$ & martensitic finish temperature $\left[{ }^{\circ} \mathrm{C}\right]$ & -6.5 \\
\hline
\end{tabular}




\subsection{Suspension by Pre-tensioned Wires Model}

Both Fig. 11(a) and Fig. 11(b) illustrate schematically how the suspension (SPW) is connected to the bearing \#2. Besides, these two figures illustrate the geometry of the suspension, so that some basic parameters for the problem formulation, such as $a_{0}=x_{p}$, $a_{1}=x_{p}-x_{b}$ and $a_{2}=x_{p}+x_{b}$ that defines how much tensioned the wires are, where $x_{p}$ and $x_{b}$ are, respectively, the pre-tension and bearing displacements. Moreover, the parameter $b_{0}=L$ is half-length of the wire. If the bearing \#2 is still or is passing through the equilibrium position only the pre-tension due to $x_{p}$ is activated and consequently $\alpha_{i}=\tan ^{-1}\left(a_{i} / b_{0}\right)$ can be defined. It is important to emphasize that this SMA elongation system actuates only at the bearing $\# 2$ along the $x$-axis. It should be noted that in the end the wires work as nonlinear springs. All these predefined parameters will be used later in the modeling of SPW.

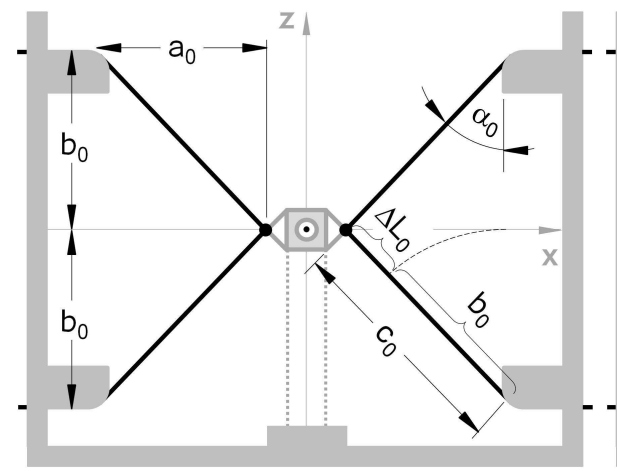

(a)

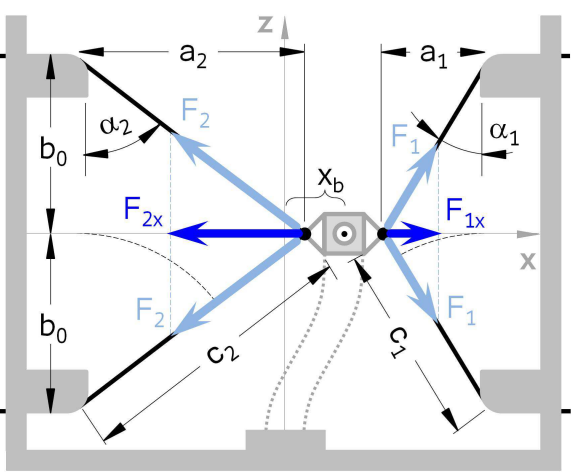

(b)

Figure 11: Schematic of the suspension system (SPW): (a) rotor at rest and (b) rotor in operation. (dotted lines $\rightarrow$ flexible frame)

Consequently, based on the aforementioned figures, the elongation of the wire can be expressed by $\Delta L=\epsilon_{0} L$, where $\epsilon_{0}$ is the engineering strain due to the pre-tension applied to the wires. Besides, by using Pythagorean theorem the parameters $c_{1}$ and $c_{2}$ are calculated in order to define the suspension geometry. Regarding the forces exerted by the suspension, due to the symmetry (upper and lower parts) it is necessary to duplicate and project $F_{1}=\sigma_{1} A$ and $F_{2}=\sigma_{2} A$ on the $x$-axis. Therefore, based on geometrical relations found in Fig. 11(b) the force $F_{1_{x}}$ that pulls the bearing \#2 to the right is given by

$$
\begin{aligned}
F_{1_{x}} & =2 F_{1} \sin \alpha_{1} \\
& =2 F_{1}\left(\frac{a_{1}}{c_{1}}\right) \\
& =\frac{2 \sigma_{1} A\left[c_{0} \sin \alpha_{0}-x_{b}\right]}{\sqrt{x_{b}^{2}-2 x_{b} c_{0} \sin \alpha_{0}+c_{0}^{2}}}
\end{aligned}
$$

whereas the antagonistic force $F_{2_{x}}$ is given by 


$$
\begin{aligned}
F_{2_{x}} & =2 F_{2} \sin \alpha_{2} \\
& =2 F_{2}\left(\frac{a_{2}}{c_{2}}\right) \\
& =\frac{2 \sigma_{2} A\left[c_{0} \sin \alpha_{0}+x_{b}\right]}{\sqrt{x_{b}^{2}+2 x_{b} c_{0} \sin \alpha_{0}+c_{0}^{2}}}
\end{aligned}
$$

where, $c_{0}=L\left(1+\epsilon_{0}\right)$ is the length of wire due to pre-tension when the suspension is still, as previously described in Fig. 11.

Thus, according to the reference frame, the total force $F_{s}$ applied by the SPW to the rotor through the bearing $\# 2$ can be written as:

$$
F_{s}=F_{1_{x}}-F_{2_{x}}
$$

As can be noticed, the forces $F_{1_{x}}, F_{2_{x}}$, and consequently $F_{s}$, are dependent on the stress $\sigma$, which in turn is calculated and updated iteratively by using the SMA Constitutive Model described in this section 3.2. It is worth remembering that $F_{s}$ is an external force within the model described by the Eq. (2). In other words, the compatibility between the model and the physics associated to the problem was preserved.

\subsubsection{Calculating the pre-tension in the SPW:}

Here, by using the formulation for the current SMA constitutive model together with the geometry of the SPW, two graphs are generated. The first relates the martensite volume fraction $\xi$ with an initial strain $\epsilon_{0}$ (due to pre-tension) and the temperature $T$, as shown in Fig. 12(a). The other graph, as can be seen in Fig. 12(b), relates the pretension displacement $x_{p}$ with the initial strain $\epsilon_{0}$ and the wire angle $\alpha_{0}$ (as a consequence of $x_{p}$ ). As previously established, the goal is to provide only a tension region in the mechanical loading history. In order to guarantee this condition, a value for the pretension displacement $x_{p}$ has been chosen such that $\xi_{0}=50 \%$. As depicted in the figures mentioned above, the values for the parameters of interest are $x_{p}=17 \mathrm{~mm}$ (that yields an wire angle $\alpha_{0}=12 \mathrm{deg}$ ) and $\epsilon_{0}=3 \%$. In addition, the hysteresis effect is only significant at high pre-tension levels. Furthermore, it is worth mentioning that all these parameters are essential to initialize the computational code responsible to simulate the dynamic behavior of the rotor system suspended by SMA wires.

\section{Results and Discussions}

The performance of the suspension (SPW) was tested for four operating conditions, namely, rotor at rest and transient rotation (run-up) for three different temperatures, besides steady-state rotation at first critical speed for several temperatures and steadystate rotation at first critical speed with varying temperature. For the first test the excitation comes from an impact and for the other cases the excitation is provided by the unbalance. 
(a)

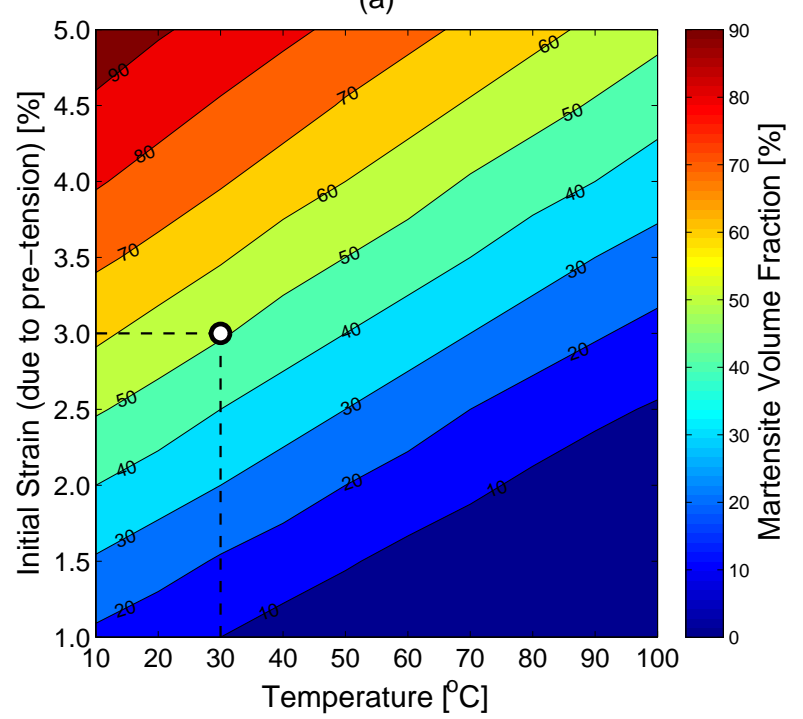

(b)

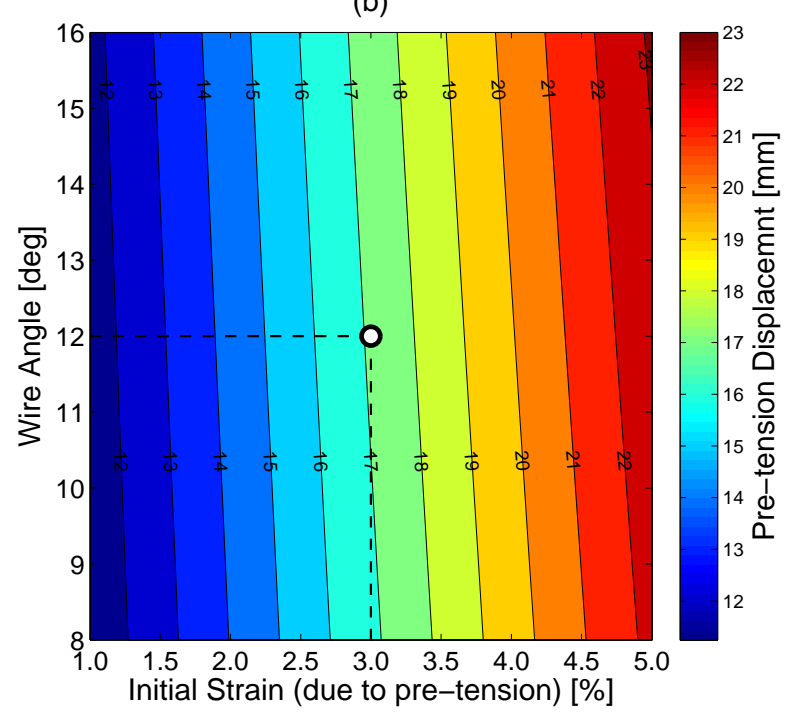

Figure 12: (a) Martensite volume fraction with respect to the initial strain (due to pretension) and to the temperature $\xi\left(\epsilon_{0}, T\right)$; (b) pre-tension displacement with respect to the initial strain and the wire angle $x_{p}\left(\epsilon_{0}, \alpha_{0}\right)$. 


\subsection{Impulse response with the rotor at rest for several tempera- tures}

This test was performed with the rotor at rest for several temperatures, namely: $T=$ $30^{\circ} \mathrm{C}, \mathrm{T}=45^{\circ} \mathrm{C}$ and $\mathrm{T}=60^{\circ} \mathrm{C}$. In this sense, by using an impact hammer, three frequency response functions were generated for the horizontal and vertical directions, as depicted in Fig. 13(a) and Fig. 13(b), respectively, although the focus relies on the horizontal direction due to the suspension effectiveness in this condition. For this test, both that the excitation and the measurement sensor are located at the disc.

(a)

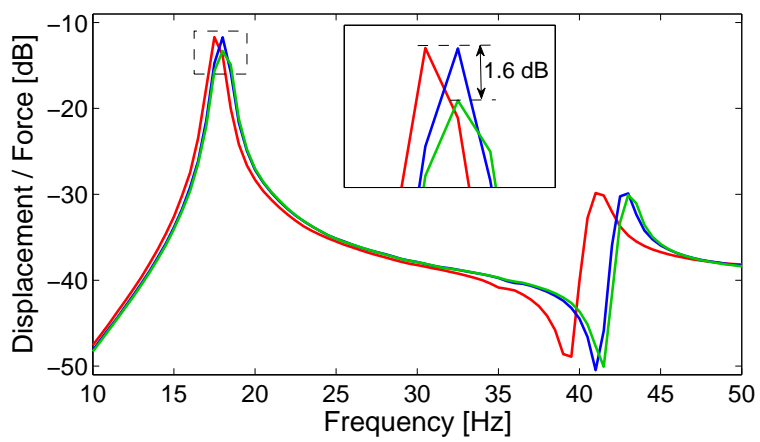

(b)

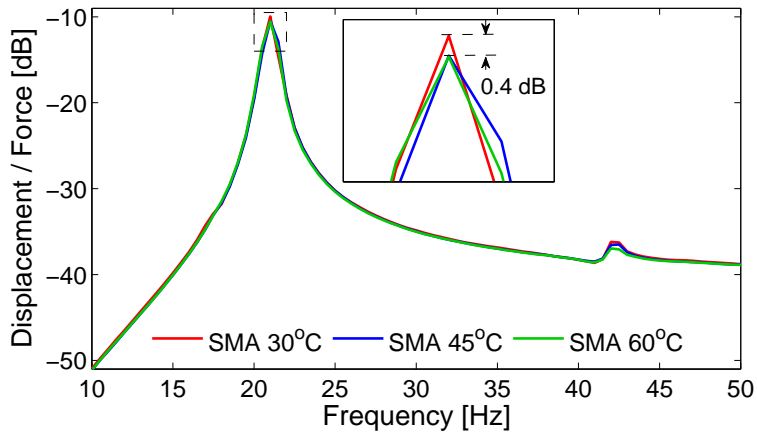

Figure 13: Experimental FRFs (estimated): (a) horizontal direction and (b) vertical direction.

For this analysis it is important to consider two points, namely: the phase transformation of SMA is dependent on the thermomechanical loading, and the suspension is only effective along to the horizontal direction. For the first mode, as shown in Fig. $13(\mathrm{a})$, from the temperature $T=30^{\circ} \mathrm{C}$ to $\mathrm{T}=45^{\circ} \mathrm{C}$ the thermal loading was enough to induce phase transformation to increase only the stiffness (denoted by the slight natural frequency shifting) whereas the mechanical loading (due to the impulsive excitation) was insufficient to induce an amount of hysteresis loops enough to increase the damping (denoted by no reduction in the peak). The other part, from $T=45^{\circ} \mathrm{C}$ to $T=60^{\circ} \mathrm{C}$, the thermomechanical loading provided a condition where the phase transformation resulted only in damping increase, as denoted by the reduction of $1.6 \mathrm{~dB}$ (or approximately 17\%) in the peak. On the other hand, based on the estimation for the vertical direction depicted in Fig. 13(b), there is no significant reduction since the peak associated to the second mode (around $21 \mathrm{~Hz}$ ) was reduced only $0.4 \mathrm{~dB}$ (or approximately 4\%). In the end, the explanation for these results is dependent on the weighting of each part of the 
thermo-mechanical loading that promotes the phase transformations as well as hysteresis cycles. In this paper the dissipated energy was not quantified, since only a qualitative analysis was performed. The results for both tests are summarized in Tab. 4 .

Table 4: Summary for impulse response results - Natural Frequencies.

\begin{tabular}{ccc}
\hline $\begin{array}{c}\text { Temperature } \\
{\left[{ }^{\circ} \mathrm{C}\right]}\end{array}$ & $\begin{array}{c}\text { Natural Frequency } \\
{[\mathrm{Hz}]}\end{array}$ & $\begin{array}{c}\text { Reduction } \\
{[\mathrm{dB}]}\end{array}$ \\
\hline \multicolumn{3}{c}{ First Mode (horizontal direction) } \\
\hline 30 & 17.5 & - \\
45 & 18.0 & 0.0 \\
60 & 18.0 & 1.6 \\
\hline \multicolumn{3}{c}{ Second Mode (vertical direction) } \\
\hline 30 & 21.0 & - \\
45 & 21.0 & 0.4 \\
60 & 21.0 & 0.4 \\
\hline
\end{tabular}

Based on the constitutive model evaluated in this contribution, the dynamic behavior obtained was expected from theory, once that the higher the temperature the lower the martensite volume fraction. In other words, the alloy (pseudoelastic wire) becomes stiffer since the Young's modulus for the austenitic phase is $58 \%$ higher than the martensitic phase (see Tab. 3). On the other hand, the transient character of the impulse response leads to a transient phase transformation. Briefly, the mechanical loading vanishes quite rapidly over time and for this reason the hysteresis loop is not capable of dissipating an important amount of energy from the structure.

\subsection{Steady-state response at first critical speed for several tem- peratures}

This section presents both simulated and experimental steady-state responses for several temperatures, as depicted in Fig. 14 and Fig. 15, respectively. The focus herein lies on showing only the responses along the horizontal direction. This decision is based on two reasons: first, only the first mode (that takes place along this direction) was evaluated in this contribution; second, the suspension (SPW) is only effective in this same direction. The alternative way to show these results is presented in Tab. 5, where the deviation rates are calculated considering experimental results as a reference.

In this case, from the point of view of vibration control, the suspension (SPW) accomplished its task. This statement is based on the results conveyed. In this operating condition, the vibration level is the highest and for this reason the phase transformation takes place during all the time test. Figure 16 shows that hysteresis loop is more upward inclined for the higher temperature, such that the higher the temperature the stiffer the suspension. It is worth mentioning that the shaft of the rotor-bearing system used in this work is very thin (only $6 \mathrm{~mm}$ ) and therefore very flexible. In this case, by assuming a conventional material for the wire (such as the steel), as the bearing stiffness increases the vibration amplitude of the disc increases as well (Muszynska, 2005). However, by using 


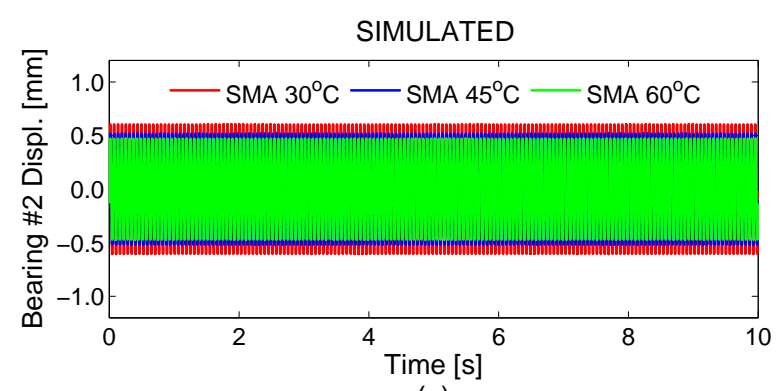

(a)

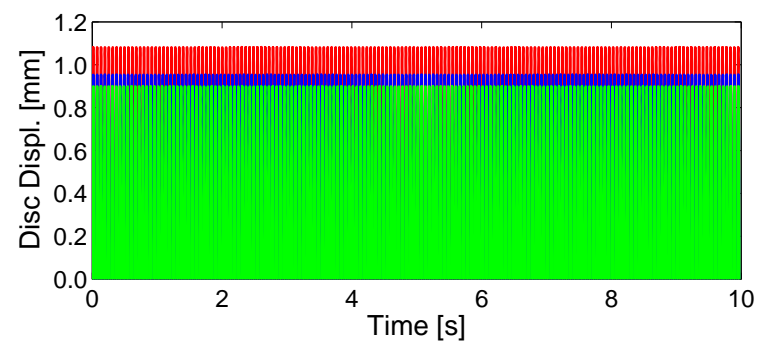

(b)

Figure 14: Simulated steady-state response at first critical speed and constant temperature in the SPW: (a) bearing \#2 displacement (node \#16) and (b) disc displacement (node $\# 12)$.

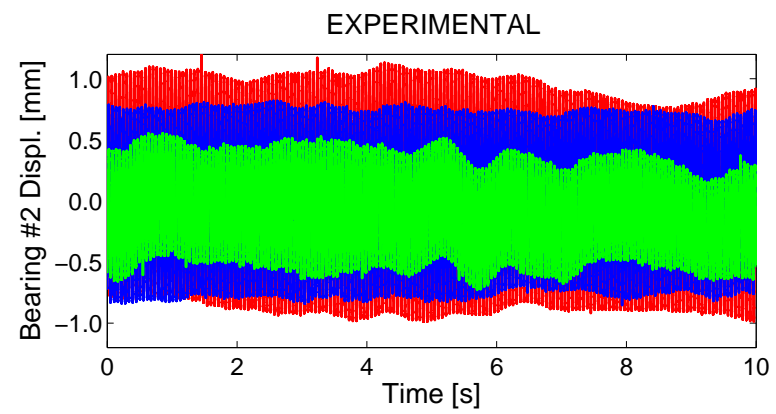

(a)

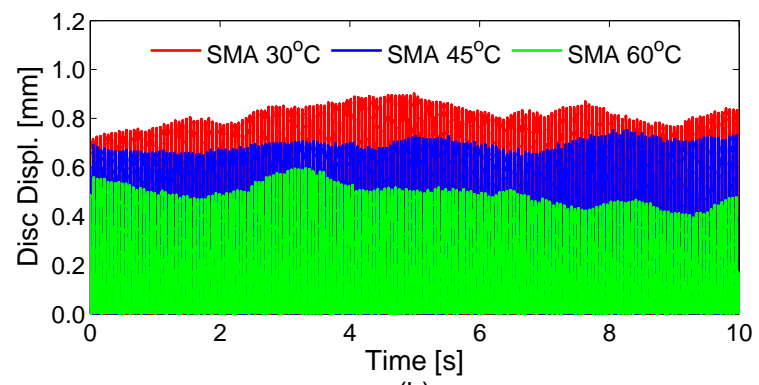

(b)

Figure 15: Experimental steady-state response at first critical speed and constant temperature in the SPW: (a) bearing \#2 displacement and (b) disc displacement. 
Table 5: Comparison between Experimental and Simulated results - steady-state response at first critical speed for several temperatures.

\begin{tabular}{cccc}
\hline $\begin{array}{c}\text { Temp. } \\
{\left[{ }^{\circ} \mathrm{C}\right]}\end{array}$ & $\begin{array}{c}\text { Experimental } \\
{[\mathrm{mm}]}\end{array}$ & $\begin{array}{c}\text { Simulated } \\
{[\mathrm{mm}]}\end{array}$ & $\begin{array}{c}\text { Deviation } \\
{[\%]}\end{array}$ \\
\hline \multicolumn{4}{c}{ Bearing \#2 (pk-pk) } \\
\hline 30 & 1.97 & 1.19 & 40 \\
45 & 1.49 & 1.03 & 31 \\
60 & 1.24 & 0.92 & 26 \\
\hline \multicolumn{4}{c}{ Disc } \\
\hline 30 & 0.81 & 1.08 & -34 \\
45 & 0.67 & 0.95 & -42 \\
60 & 0.48 & 0.90 & -87 \\
\hline
\end{tabular}

pseudoelastic SMA wires, a stiffer suspension was capable of providing lower vibration amplitude for the disc, in such a way that it can be concluded that the main reason for the reported reductions is most likely due to energy dissipation.

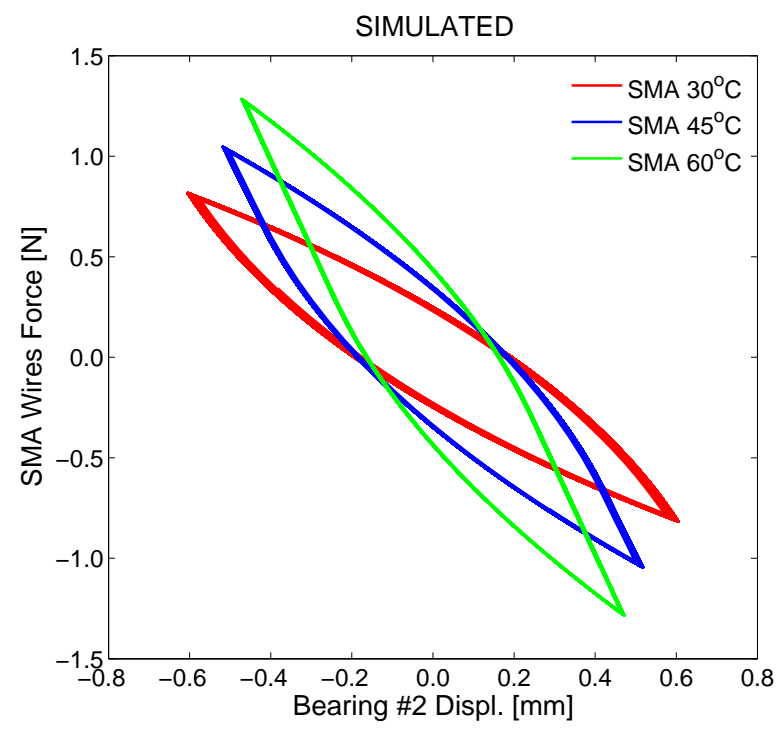

Figure 16: Simulated histeresys loop at first critical speed and constant temperature in the SPW.

\subsection{Steady-state response at first critical speed with varying tem- perature}

In this section the results for numerical and experimental evaluations are presented. Here, the rotor operates at constant speed of rotation and the suspension is submitted to varying temperature. It is important to say that the idea was to operate the rotor as close as possible to the first natural frequency. For this reason, in both cases the 
speed of rotation was shifted only $2 \%$ from the respective natural frequencies. Thus, for the simulation and the experimental tests the rotational speed was set to $984 \mathrm{rpm}$ and $1080 \mathrm{rpm}$, respectively. The choice of the rotation speed close to the critical speed is to provide large vibration amplitude, being enough to induce phase transformation in the SMA wires of the suspension. Regarding the heating process, the Fig. 17(a) and Fig. 18(a) show the temperature time history. In addition, note that the experimental curve was used to run the simulation test looking for more reliable results. As the suspension (SPW) was located at bearing \#2 the presentation of the results begins with the corresponding displacements at this point, so that the Fig. 17(b) and Fig. 18(b) illustrate the simulated and the experimental cases, respectively. The simulated and experimental displacements of the disc are shown, respectively, in Fig. 17(c) e Fig. 18(c). As done before, the hysteresis loops were simulated, specifically at $t=2 \mathrm{~s}$ and $t=32 \mathrm{~s}$. Thus, the suspension stiffness increases over time, as revealed by Fig. 19. This fact justifies the reduction of the vibration amplitude because the difference between the natural frequency (that increases over time) and the given operational frequency becomes larger. In other words, the rotor runs away from the resonant condition whenever the temperature increases. Therefore, all reduction rates regarding this evaluation can be observed in Tab. 6 .

Table 6: Reduction rates for varying temperature evaluation.

\begin{tabular}{ccc}
\hline & Experimental & Simulated \\
\hline Bearing \#2 & $64.6 \%$ & $22.4 \%$ \\
Disc & $51.9 \%$ & $15.8 \%$ \\
\hline
\end{tabular}

\subsection{Transient response (run-up) for several temperatures}

In this case, the unbalanced rotor was subjected to a constant acceleration of $60 \mathrm{rpm} / \mathrm{s}$ from stand still. The results for this scenario, both simulated and experimental, are presented, respectively, in Fig. 20(a),(b) and Fig. 21(a),(b). As previously, the results are also shown in tabular form, as can be seen in Tab. 8. It is worth mentioning that only the range of interest (first mode) is focused on the studied application.

By observing the simulated and experimental responses, they do not correspond quantitatively. However, the difference found between the two cases are related to the assumptions that will be discussed later in the present paper. Another point is the fact that the critical speed of the rotor is temperature dependent, as commented and justified previously, where the higher the temperature, the larger the critical speed of the rotor, as can be seen in Tab. 7. Regarding the experimental case, two aspects were considered, as shown in Tab. 9. First, the focus relied on the response for each temperature; then, a potential way to cool down the wires in the suspension of the rotor was tested.

In the first experimental approach, considering the response for the temperature $T=$ $30^{\circ} \mathrm{C}$ as being the reference, the reduction rate, as presented in Tab. 9, is $2.6 \%$ from the point $\mathrm{A}$ to the point $\mathrm{B}$, and $18.2 \%$ from the point B to C. For this last case, the result is interesting, especially because the power consumption to heat the suspension up to $T=60^{\circ} \mathrm{C}$ in a few seconds is not high, since it is a run-up operation. On the other hand, for the second experimental approach (not performed in this work), a hypothetical scenario 


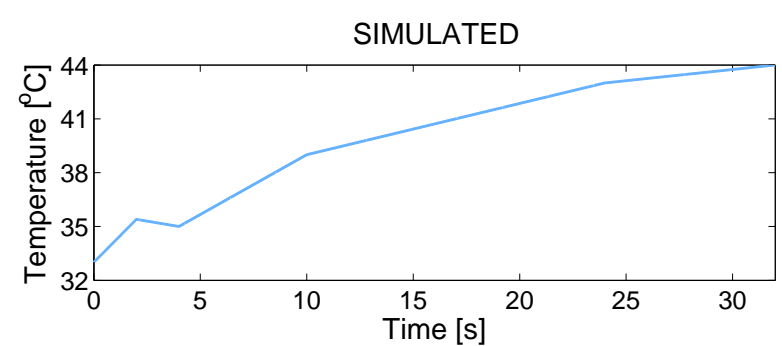

(a)

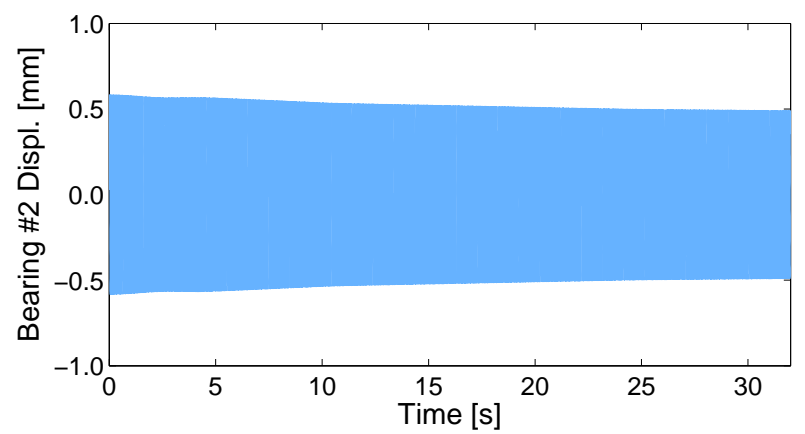

(b)

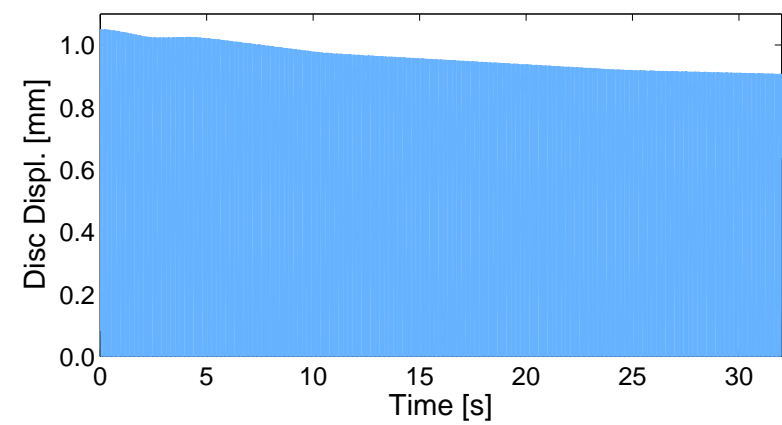

(c)

Figure 17: Simulated steady-state response at first critical speed and varying temperature in the SPW: (a) temperature time history, (b) bearing \#2 displacement (node \#16) and (c) disc displacement (node \#12).

Table 7: Comparison between Experimental and Simulated results - critical speeds (first mode) for transient response (run-up) speed for several temperatures.

\begin{tabular}{ccc}
\hline Temp. $\left[{ }^{\circ} \mathrm{C}\right]$ & \multicolumn{2}{c}{ Critical Speed $[\mathrm{Hz}]$} \\
& Experimental & Simulated \\
\hline 30 & 17.6 & 17.2 \\
45 & 17.8 & 17.3 \\
60 & 18.2 & 17.5 \\
\hline
\end{tabular}




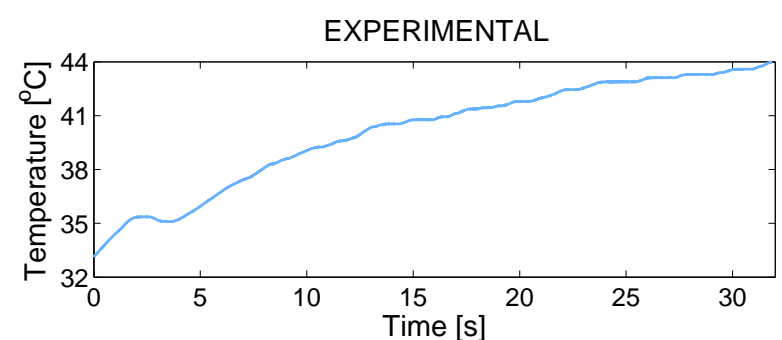

(a)

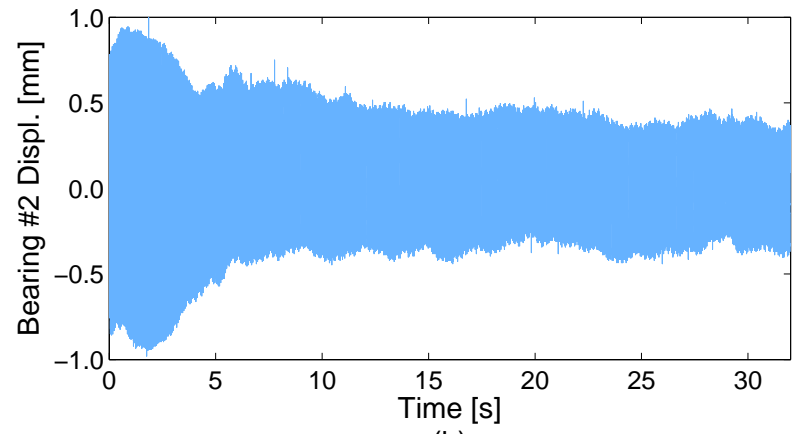

(b)

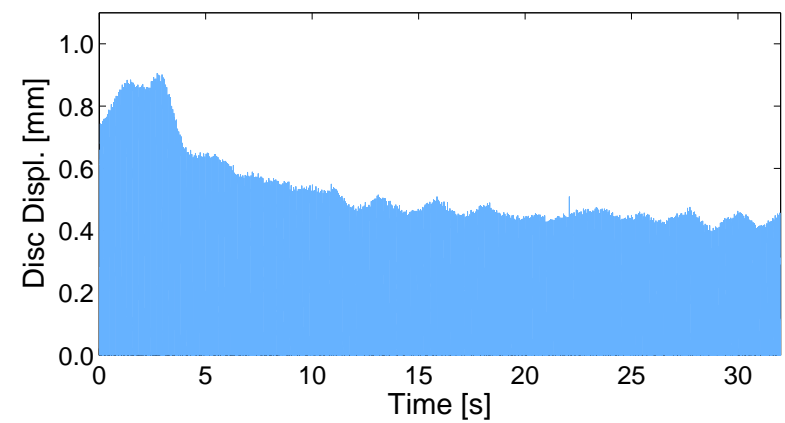

(c)

Figure 18: Experimental steady-state response at first critical speed and varying temperature in the SPW: (a) temperature time history, (b) bearing \#2 displacement and (c) disc displacement.

Table 8: Comparison between Experimental and Simulated results - transient response (run-up) speed for several temperatures.

\begin{tabular}{cccc}
\hline $\begin{array}{c}\text { Temp. } \\
{\left[{ }^{\circ} \mathrm{C}\right]}\end{array}$ & $\begin{array}{c}\text { Experimental } \\
{[\mathrm{mm}]}\end{array}$ & $\begin{array}{c}\text { Simulated } \\
{[\mathrm{mm}]}\end{array}$ & $\begin{array}{c}\text { Deviation } \\
{[\%]}\end{array}$ \\
\hline \multicolumn{5}{c}{ Bearing \#2 } \\
\hline (pk-pk) \\
40 & 1.56 & 1.09 & 30 \\
60 & 1.44 & 0.96 & 33 \\
\hline \multicolumn{5}{c}{ Disc } \\
\hline 30 & 1.23 & 0.89 & 28 \\
45 & 0.77 & 0.95 & -23 \\
60 & 0.75 & 0.88 & -17 \\
\hline
\end{tabular}




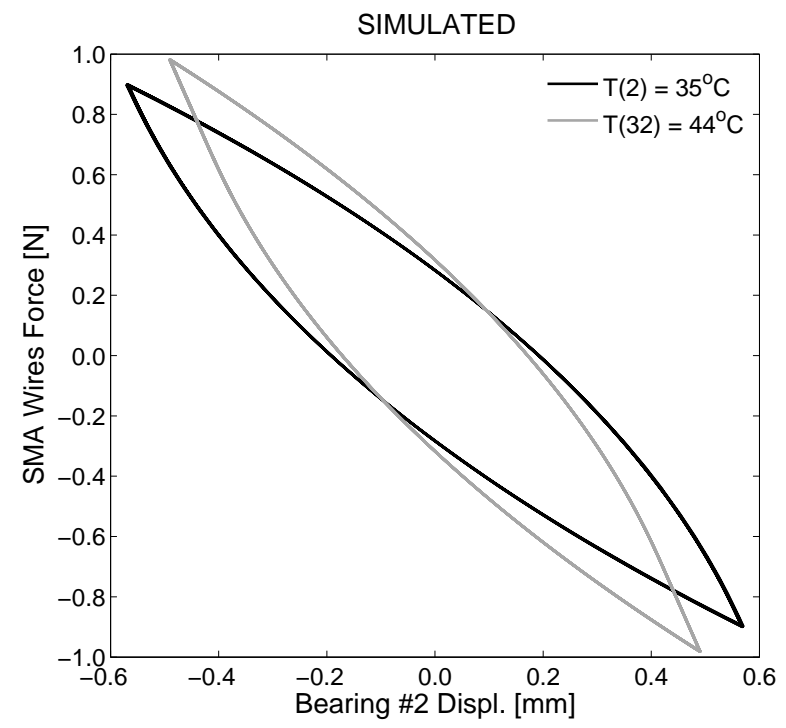

Figure 19: Simulated histeresys loop at first critical speed and varying temperature in the SPW.

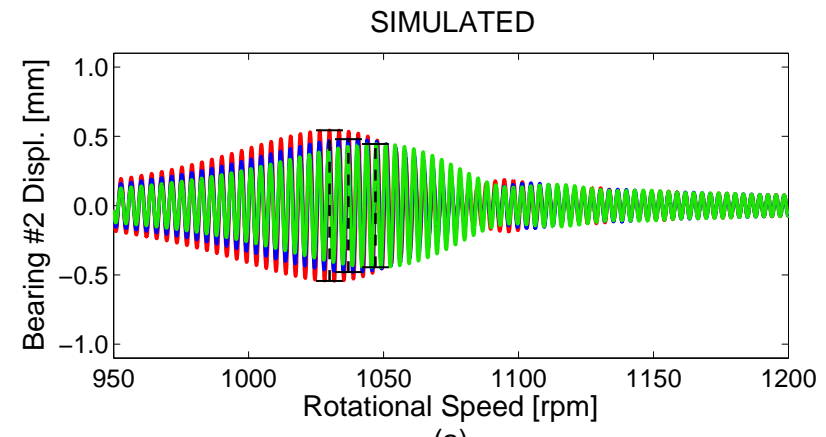

(a)

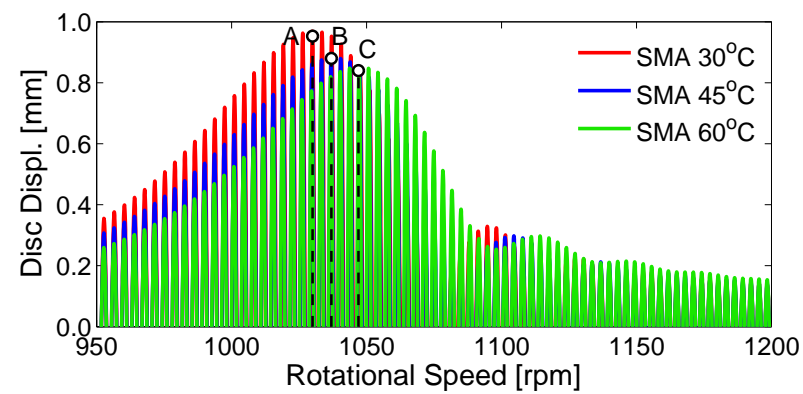

(b)

Figure 20: Simulated transient response: (a) bearing \#2 displacement (node \#16) and (b) disc displacement (node \#12). 


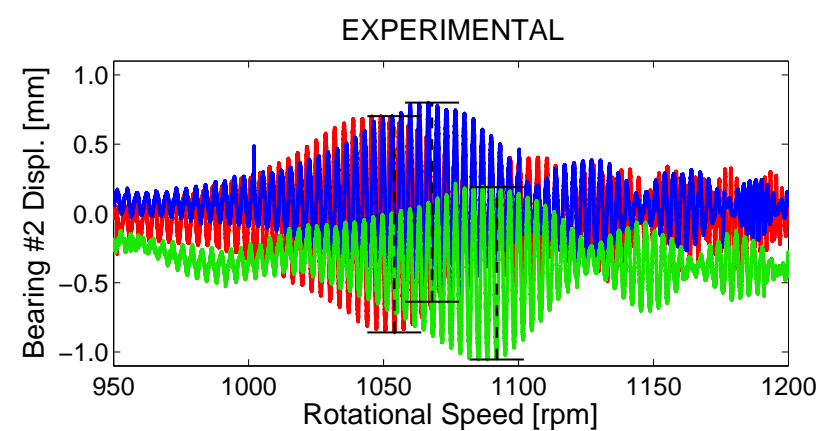

(a)

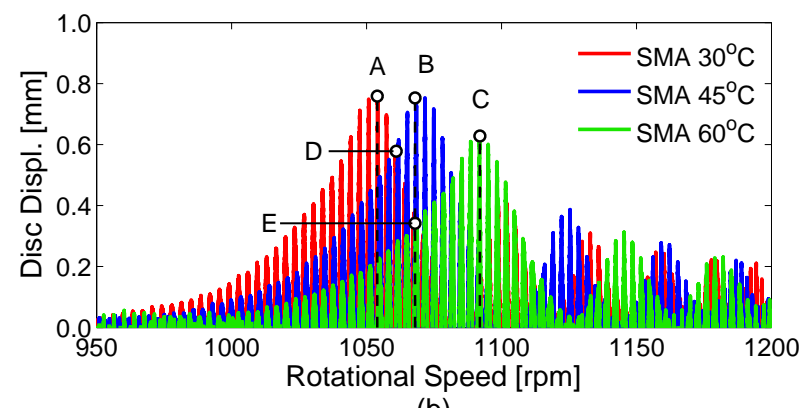

(b)

Figure 21: Experimental transient response: (a) bearing \#2 displacement and (b) disc displacement.

was considered, where the rotor (with the SMA wires of the suspension at $T=45^{\circ} \mathrm{C}$ or $T=60^{\circ} C$ ) would pass through critical speed (represented by the reference response) during the rotor acceleration phase and immediately after this the suspension would be cooled rapidly, analogously to the principle used by Nie and Yan (2000), as can be observed in Fig. 21(b). In this case the estimated reduction rates is $24.9 \%$ from the point A to the point $\mathrm{D}$, and $55.8 \%$ from the point $\mathrm{A}$ to the point $\mathrm{E}$. Therefore, for this case, the performance of the suspension is noticeably higher than the one revealed by the first approach. It is important to mention that, as for the first approach, the heating power consumption would not be an issue. Consequently, differently from what occurred in the section devoted to the response, here the vibration of the rotor is higher and more lasting than the one that results from the impulse response and for this reason it is capable of inducing a high level of phase transformation in the SMA wires due to thermomechanical loading. Then, all these phenomena studied most likely represent a larger amount of dissipated energy or, in other words, more damping effect was added to the system despite of the stiffer suspension used, as justified in the section devoted to steady-state responses for the first critical speed.

\subsection{Comments on the key assumptions}

For all cases studied above, the performance of the suspension (SPW), as demonstrated by the experimental results, was better than the results obtained from the simulation in terms of vibration reduction. This means that, the performance of the model is deeply linked to the assumptions that were made to construct the model. These assumptions are 
Table 9: Simulated and Experimental reduction rates for the disc displacements.

\begin{tabular}{cccccc}
\hline \multicolumn{2}{c}{ Simulated } & \multicolumn{4}{c}{ Experimental } \\
\hline \multicolumn{2}{c}{ Approach 1 } & \multicolumn{2}{c}{ Approach 1 } & \multicolumn{2}{c}{ Approach 2 } \\
\hline Temp. & Red. & Temp. & Red. & Temp. & Red. \\
{$\left[{ }^{\circ} C\right]$} & {$[\%]$} & {$\left[{ }^{\circ} C\right]$} & {$[\%]$} & {$\left[{ }^{\circ} C\right]$} & {$[\%]$} \\
\hline 30 & - & 30 & - & 30 & - \\
$45(A B)$ & 7.7 & $45(A B)$ & 2.6 & $45(A D)$ & 24.9 \\
$60(A C)$ & 11.8 & $60(A C)$ & 18.2 & $60(A E)$ & 55.8 \\
\hline
\end{tabular}

now discussed in the following.

1. The temperature along the wire is equal to the temperature of the environment: in real world suspensions the heating chamber is not hermetically sealed. Besides, its geometry is not able to provide a uniform air flow distribution and, consequently, an unequal thermal field results;

2. Constant temperature in the wire cross sectional area: for this reason the diameter of wire was chosen as $0,25 \mathrm{~mm}$; however, this condition does not avoid a non uniform temperature distribution;

3. Thermal expansion of SMA wire is neglected: Due to thermal expansion the (stressfree) length of the SMA wires increases with temperature. This means the pretension length and pre-tension force decreases with temperature. This phenomenon is neglected in the model and could therefore be a strong assumption;

4. Self-heating of SMA wire is neglected: whenever a cyclic mechanical loading takes place self-heating is induced, which amplifies the effect of the environmental temperature;

5. Thermomechanical properties of SMA wire are deterministic: actually, no matter how good the characterization process is, the parameters always carry a certain level of uncertainty;

\section{Concluding Remarks}

Numerical simulations have been carried out for a rotor-bearing system suspended by pre-tensioned wires (SPW) in which pseudoelastic SMA wires are used to control the dynamic response of the system. In this sense, a modified Brinson's model was used to describe the SMA wire behavior when subjected to thermomechanical loading. It was shown that for all tests performed, the results reveal that the higher vibration and the higher temperature the higher damping effect will be expected from the SMA suspension. This conclusion is supported by the amplitude reduction that was observed for the rotorbearing system.

For the impulse response with the rotor at rest, the suspension was capable of reducing slightly the amplitude since the response due to impact vanishes rapidly in such a way 
that the duration of the phase transformation (migration from martensite to austenite and vice-versa) is extremely short. By analyzing the transient response, it was observed that the performance of the suspension was even better because in the run-up operation, the amplitude vibration becomes larger as the rotor passes through the critical speed, thus potentializing the phase transformation and, consequently, the damping effect (energy dissipation). Besides, if the possibility of cooling the SMA suspension down after the rotor passes through the critical speed (baseline at $T=30^{\circ} \mathrm{C}$ ) is assured, the performance is significantly enhanced. Specifically, in the test with the rotation speed close to the first critical speed and varying temperature, an interesting behavior was captured. In this case, the response showed that the vibration amplitude decreases as the temperature was increased. Consequently, this peculiar behavior suggests that a suspension built with pseudoelastic SMA wire could be applied to rotating machines as a safety device in cases where the vibration level is suddenly increased. Therefore, the machine shutdown is avoided until maintenance procedure is performed. Then, the previous technique suggests a temporary self-healing approach for the rotor-bearing system by implementing a control law.

It was demonstrated that the dynamic behavior of the system should be evaluated according to two important parameters, namely the hysteresis and stiffness. An important result of the present investigation is that the numerical model was capable of providing a reasonable qualitative agreement with the experimental results. For this reason, a natural topic for further research is to investigate the assumptions that were made to construct the model of the rotor-bearing system suspended by SMA wires. Anyway, the overall results showed that the SMA is efficient to reduce the vibration level of the system and can be used as an alternative solution to passive vibration control of rotating systems. Another important point is that for relatively low temperatures (in comparison with room temperature), for low heating power consumption (heating for short periods), the vibration reduction was significant.

Finally, based on the results above it is possible to say that SMA wires represent an interesting alternative for semi-active rotor vibration control. In addition, the use of SMA in this context complies with the requirement of low energy consumption, as expected for the so-called eco-rotors.

\section{Acknowledgements}

The authors are thankful to Brazilian Research Agencies such as CNPq and CAPES (supported by process BEX 11550/12-0) and to the Technical University of Denmark (supported by FTP research project 12-127502). The authors are also thankful to CNPq and FAPEMIG Brazilian Research Agencies for their support through INCT-EIE.

\section{References}

Alves MTS (2015) Vibration Control of Rotating Machinery using Shape Memory Alloys, PhD Thesis (in Portuguese), Universidade Federal de Uberlândia, Brazil.

Alves MTS, Enemark S, Steffen Jr V and Santos IF (2015) Vibration Control of a Flexible 
Rotor Using Shape Memory Alloy Wires, In Proceedings of the XVII International Symposium on Dynamic Problems of Mechanics, Natal-RN-Brazil.

Atepor L (2008) Vibration Analysis and Intelligent Control of Flexible Rotor Systems using Smart Materials, PhD Thesis, University of Glasgow.

Bekker A and Brinson LC (1998) Phase Diagram based Description of the Hysteresis Behavior of Shape Memory Alloys, Acta Materials, 46, 3649-3665.

Borges JM, Silva AA, Araújo CJ, Fernandes EM, Pimentel RL and Santiago AA (2013) Rotor-Bearing Vibration Control System based on Fuzzy Controller and Smart Actuators, International Journal of Multiphysics, 7(3), pp. 197-205.

Brinson LC (1993) One-Dimensional Constitutive Behavior of Shape Memory Alloys: Thermomechanical Derivation with Non-Constant Material Functions and Refefined Martensite Internal Variable, Journal of Intelligent Material Systems and Structures 4.

Brinson LC and Huang MS (1996) Simplifications and Comparisons of Shape Memory Alloy Constitutive Models, Journal of Intelligent Material Systems and Structures January, 7, 108-114.

Enemark S, Savi MA and Santos IF (2014) Nonlinear Dynamics of a Pseudoelastic Shape Memory Alloy System - Theory and Experiment, Smart Material and Structures 23.

Enemark S, Santos IF and Savi MA (2015) Shape Memory Alloys applied to Improve Rotor-Bearing System Dynamics - An Experimental Investigation, In Proceedings of the XVII International Symposium on Dynamic Problems of Mechanics, Natal, Brazil.

Enemark S and Santos IF (2016a) Rotor-Bearing System Integrated with Shape Memory Alloy Springs for Ensuring Adaptable Dynamics and Damping Enhancement - Theory and Experiment, Journal of Sound and Vibration, 369, pp. 29-49.

Enemark S and Santos IF (2016b) Quasi-static Characterisation of Trained Pseudoelastic Shape Memory Alloy Wire subjected to Cyclic Loading: Transformation Kinetics, Journal of Intelligent Material System and Structures, Vol. 27(9), pp. 1150-1164.

Gupta K, Sawhney S, Jain SK and Darpe A (2003) Stiffness Characteristics of Fiber Reinforced Composite Shaft Embedded with Shape Memory Alloy Wires, Defence Science Journal, 53, pp. 167-173.

He YY, Oi S, Chu FL and Li HX (2007a) Vibration Control of a Rotor-Bearing System using Shape Memory Alloy: I. Theory, Smart Materials and Structures 16.

He YY, Oi S, Chu FL and Li HX (2007b) Vibration Control of a Rotor-Bearing System using Shape Memory Alloy: II. Experimental Study, Smart Materials and Structures 16.

Lalanne M and Ferraris G (1997) Rotordynamics Prediction in Engineering, 2nd edition, John Wiley and Sons, New York. 
Lees AW, Jana S, Inman DJ and Cartmell MP (2007) The Control Of Bearing Stiffness Using Shape Memory, IMAC-XXV: Conference \& Exposition on Structural Dynamics.

Liu B, Yan L, Li Q and Zhu ZW (1994) Vibration Control of a Rotor System utilizing a Bearing Housing with Controllable Spring Nonlinearity, In Proceedings of ASME 1994 International Gas Turbine and Aeroengine Congress and Exposition, volume 5, Hague.

Ma Y, Zhang Q, Zhang D, Scarpa F, Liu B and Hong J (2014) A Novel Smart Rotor Support with Shape Memory Alloy Metal Rubber for High Temperatures and Variable Amplitude Vibrations, Smart Materials and Structures, 23(12).

Muszynska A (2005) Rotordynamics, 1nd edition, CRC Press, Boca Raton.

Nagaya K, Takeda S, Tsukui Y and Knmaido Y(1987) Active Control Method for Passing Through Critical Speeds of Rotating Shafts by Changing Stiffness of the Supports with use of Memory Metals, Journal of Sound and Vibration, 113(2), pp. 307-315.

Nie J and Yan X (2000) Intelligent Bearing System for Passing through Critical Speed of Aeroengine Rotor by Changing Stiffness using SMA Wires, Journal of Sound and Vibration, 113(2), pp. 307-315.

Silva LC, Savi MA and Paiva A (2013) Nonlinear Dynamics of a Rotordynamic Nonsmooth Shape Memory Alloy System, Journal of Sound and Vibration, 332, 608-621.

Zhu ZW, Wang HL and Xu J (2009) Application on Rotor Vibration Control of SMA Model Based on Multivariate Statistical Analysis, World Congress on Computer Science and Information Engineering.

Yogaraju R, Ravikumar L, Saravanakumar G, Shravankumar C and Arun Kumar V (2016) Feasibility and Performance Studies of a Semi Active Journal Bearing, Procedia Technology, 25, pp. 1154-1161 .

Yuan H, Fauroux JC, Chapelle F and Balandraud X (2017) A Review of Rotary Actuators based on Shape Memory Alloys, Journal of Intelligent Material System and Structures, Vol 28, Issue 14. 